Citation: G. Babaei, S.A. Esmaeilzadeh-Hosseini, M. Zandian, V. Nikbakht (2020) Identification of phytoplasma strains associated with witches' broom and yellowing in Ziziphus jujube nurseries in Iran. Phytopathologia Mediterranea 59(1): 55-61. doi: 10.14601/ Phyto- 10857

Accepted: December 6, 2019

Published: April 30, 2020

Copyright: (c) 2020 G. Babaei, S.A. Esmaeilzadeh-Hosseini, M. Zandian, V. Nikbakht. This is an open access, peer-reviewed article published by Firenze University Press (http://www. fupress.com/pm) and distributed under the terms of the Creative Commons Attribution License, which permits unrestricted use, distribution, and reproduction in any medium, provided the original author and source are credited.

Data Availability Statement: All relevant data are within the paper and its Supporting Information files.

Competing Interests: The Author(s) declare(s) no conflict of interest.

Editor: Assunta Bertaccini, Alma Mater Studiorum, University of Bologna, Italy.

\section{Research Paper \\ Identification of phytoplasma strains associated with witches' broom and yellowing in Ziziphus jujube nurseries in Iran}

\author{
Ghobad BABAEI ${ }^{1, *}$, Seyyed Alireza ESMAEILZADEH-HOSSEINI ${ }^{2}, \mathrm{MaH}^{-}$ \\ вовен ZANDIAN ${ }^{1}$, VAHID NIKBAKHT ${ }^{3}$ \\ ${ }^{1}$ Plant Protection Research Department, Chaharmahal and Bakhtiari Agricultural and \\ Natural Resources Research and Education Center, AREEO, Shahrekord, Iran \\ ${ }^{2}$ Plant Protection Research Departments, Yazd Agricultural and Natural Resources \\ Research and Education Center, AREEO, Yazd, Iran \\ ${ }^{3}$ Chaharmahal and Bakhtiari Agricultural Organization, Shahrekord, Iran \\ ${ }^{\star}$ Corresponding author: ghobad.babaee@gmail.com
}

\begin{abstract}
Summary. Phytoplasma symptoms, including proliferation, witches' broom, leaf rolling and yellowing, were observed in jujube (Ziziphus jujube) nurseries in the East of Iran. Total nucleic acid was extracted from symptomatic and symptomless plants, and was tested for phytoplasma presence using nested PCR. Amplicons of about $1.8 \mathrm{~kb}$ (primer pair P1/P7) and $1.25 \mathrm{~kb}$ (R16F2n/R16R2) were obtained from all symptomatic plants but not from symptomless plants. Restriction fragment length polymorphism (RFLP) analysis of R16F2n/R2 amplicons using KpnI, HaeIII, RsaI, AluI, HpaII, HhaI, TaqI, MseI, BfaI and ThaI restriction enzymes showed two RFLP patterns referable to 16SrI and 16SrVI phytoplasma groups. The consensus sequences of $Z$. jujube yellowing and witches' broom of six samples correspond to 'Candidatus Phytoplasma asteris' and 'Candidatus Phytoplasma trifolii'-related strains. Two R16F2n/R16R2 16S rDNA sequences representative of each RFLP profile, one each from witches' broom (accession number MK379605) and yellowing (MK379604) host symptoms, were submitted to the GenBank. Phylogenetic analysis confirmed that the phytoplasma strains associated with jujube yellowing clustered within the 16 SrI phytoplasma clade, and those associated with witches' broom clustered within the 16 SrVI clade. Restriction analysis confirmed that virtual RFLP patterns of the jujube yellowing and witches' broom phytoplasma strains were identical to the reference pattern of $16 \mathrm{SrI}-\mathrm{B}$ and $16 \mathrm{SrVI}-\mathrm{A}$. This is the first report of these phytoplasma strains associations with witches' broom and yellowing in jujube plants.
\end{abstract}

Keywords. Aster yellows phytoplasma, clover proliferation phytoplasma, jujube.

\section{INTRODUCTION}

Jujube (Ziziphus jujube Mill) is a small shrub or tree with small fruits about in the size of date, that is native to southern and central Asia and is grown in the northeast and central parts of Iran. Jujube has different cultivars, the fruit is used as food, and the plants can be used as a vegetable and for medicinal purposes. 
Jujube witches' broom (JWB) was first reported as a graft transmissible disease (Kim, 1965), as phyllody, lack of fruit production and dieback in China (La and Woo, 1980). The disease symptoms included little leaf, phyllody and leaf yellowing, and the disease is a severe production-limiting factor, distributed in all Asian countries including China, Korea and Japan. Yield losses up to of $80 \%$ have been reported, and rapid tree death can result (Tsai et al., 1988; Lee, 1988; Ohashi et al., 1996).

Phytoplasma agents associated with JWB belong to subgroup $16 \mathrm{SrV}-\mathrm{B}$, and showed the same $16 \mathrm{~S}$ ribosomal sequence in China and Korean strains (Zhu et al., 1998; Han and Cha, 2002). This phytoplasma had been described as 'Candidatus Phytoplasma ziziphi' (Jung et al., 2003), and it is transmitted by the leafhoppers Hishimonoides chinensis and H. sellatus (La and Woo, 1980). Jujube trees with symptoms of proliferation, yellowing and witches' broom were reported from $Z$. jujube and $Z$. nummularia in India, and were associated with ' $\mathrm{Ca}$. P. ziziphi'-related strains (Khan et al., 2008). Mixed infections of jujube by two phytoplasmas of groups of $16 \mathrm{SrI}$ and $16 \mathrm{SrV}-\mathrm{B}$ were reported in Korea (Lee et al., 2009).

The aim of the present study was to assess the presence of phytoplasmas in diseased jujube, and to identify the phytoplasma strains associated with proliferation, witches' broom and yellowing in jujube nurseries in the Eastern part of Iran. This information was required to plan appropriate disease management strategies.

\section{MATERIALS AND METHODS}

\section{Plant sampling}

During surveys in 2017 in the Razavi Khorasan Province in eastern Iran, witches' broom, proliferation, leaf rolling and yellowing symptoms (Figure 1) were observed in jujube nursery plants, and 22 symptomatic and four asymptomatic jujube plants were sampled and subjected to molecular analyses for phytoplasma detection and identification.

\section{DNA extraction and nested PCR amplification}

Total DNA was extracted from $0.2 \mathrm{~g}$ of midrib tissue of fresh leaves from symptomatic and symptomless $Z$. jujube nursery plants, following the procedure described by Li et al. (2005). Midrib tissue samples were ground in liquid nitrogen and homogenized in $3 \mathrm{M}$ CTAB buffer. After chlorophorm/isoamyl alcohol (24: 1) treatment, the aqueus phase was mixed with $5 \mathrm{M}$ $\mathrm{NaCl}$ and maintained for $1 \mathrm{~h}$ at $-20^{\circ} \mathrm{C}$. After precipita- tion by centrigufation, the resulting pellet was washed with $70 \%$ etanol, and the final DNA pellet was dissolved in $100 \mu \mathrm{L}$ of sterilized water. The total DNA extracted from Prunus persica yellowing and decline in Iran (' $\mathrm{Ca}$. P. omanense'-related strain) (Esmailzadeh Hosseini et al., 2017b) was used as positive control. The DNA quality and concentration were estimated by spectrophotometer and agarose gel electrophoresis, and $100 \mathrm{ng}$ of nucleic acids was used for each PCR reaction with universal primer pair P1/P7 (Deng and Hiruki, 1991; Schneider et al., 1995) to amplify parts of the rRNA operon. This included the 16S rRNA gene, 16S-23S rRNA spacer region (SR) and the 5' end of the $23 \mathrm{~S}$ rRNA gene. The amplified products $(1 \mu \mathrm{L})$ were diluted in $30 \mu \mathrm{L}$ with sterile deionized water, and $1 \mu \mathrm{L}$ of the resulting solution was used as template in nested PCR with the primer pair R16F2n/R16R2 (Gundersen and Lee, 1996). The PCR reactions were performed in $50 \mu \mathrm{L}$ mixtures containing $0.4 \mu \mathrm{M}$ of each primer, with EmeraldAmp PCR master mix (Takara). The reaction cycled 30 times in a programmable thermocycler (QuantaBiotech), with the following parameters: denaturation for $30 \mathrm{sec}$ at $94^{\circ} \mathrm{C}$ ( $2 \mathrm{~min}$ in the first round), annealing for $30 \mathrm{sec}$ at $55^{\circ} \mathrm{C}$ and primer extension for $1 \mathrm{~min}$ at $72^{\circ} \mathrm{C}(10 \mathrm{~min}$ in the final cycle). The PCR conditions for the nested PCR reaction were the same except that the annealing temperature was $58^{\circ} \mathrm{C}$. Five $\mu \mathrm{L}$ of each reaction mixture were analyzed by electrophoresis in a $1 \%(\mathrm{w} / \mathrm{v})$ agarose gel in TBE 1X buffer and visualized with a UV imaging system (Isogen Life Science) after ethidium bromide staining. The sizes of the PCR products were estimated by comparison with a 100 bp DNA ladder (Biobasic).

\section{Restriction fragment length polymorphism analyses}

Restriction fragment length polymorphism (RFLP) analyses of R16F2n/R16R2 amplicons, using KpnI, HaeIII, RsaI, AluI, HpaII, HhaI, TaqI, MseI, BfaI and ThaI restriction enzymes, were performed according to the instructions of the manufacturer (Thermo). The restriction products were then separated by electrophoresis through an $8 \%$ polyacrylamide gel, stained with ethidium bromide and visualized with a UV imaging system (Isogen Life Science). The resulting RFLP patterns were compared with those published for the same 16S rDNA amplicons of other phytoplasmas (Lee et al., 1998).

\section{Sequencing and phylogenetic analysis}

R16F2n/R16R2 primed PCR products $(1.2 \mathrm{~kb})$ from six samples of symptomatic $Z$. jujube plants from nurs- 


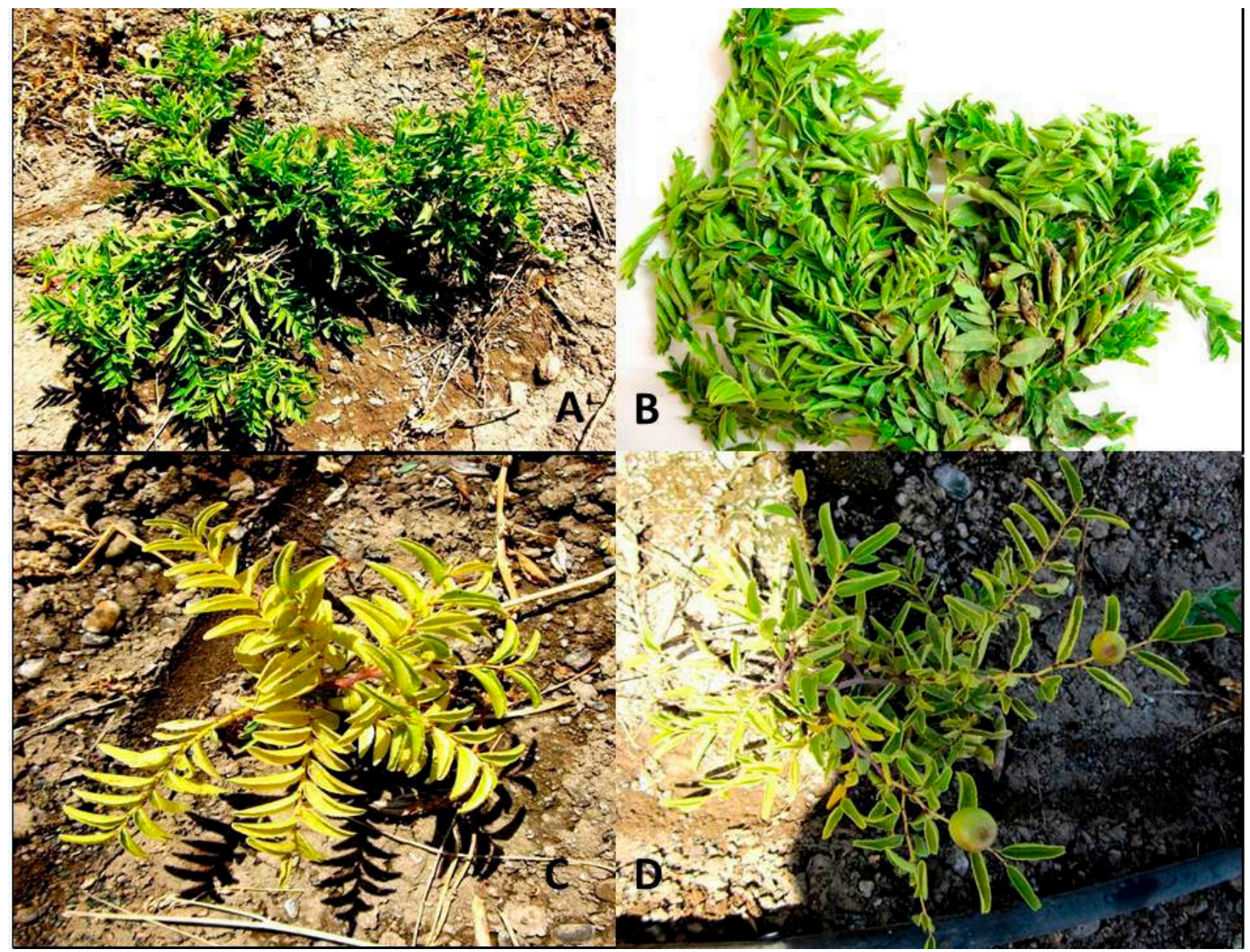

Figure 1. Phytoplasma disease symptoms on jujube plants: (A) and (B) proliferation and witches' broom, (B) and (C), (D) yellowing, leaf rolling and stunting of an infected plant.

eries in Razavi Khorasan province in eastern Iran were sequenced from both directions. Consensus assembled sequences were compared with deposited sequences in the GeneBank database using BlastN (https://blast.ncbi. nlm.nih.gov/Blast.cgi), and aligned with Bio edit tools. The 1,250 bp of 16S rDNA sequences of the two strains associated with witches' broom and yellowing of $Z$. jujube were aligned using MEGA7 software (Kumar et al., 2016), and a phylogenetic tree was constructed using the neighbor-joining method. Acholeplasma laidlawii was used as an out group to root the tree. Bootstrapping was performed 1,000 times to estimate branch stability.

\section{Virtual RFLP}

Virtual RFLP analysis using iPhyClassifier (Zhao et al., 2009) was used to confirm subgroup affiliation of phytoplasmas detected in Z. jujube plants displaying witches' broom and yellowing. The DNA fragment was digested in silico with 17 distinct restriction enzymes: AluI, BamHI, BfaI, BstUI (ThaI), DraI, EcoRI, HaeIII, HhaI, HinfI, HpaI, HpaII, KpnI, MboI (Sau3AI), MseI, RsaI, SspI and TaqI.

\section{RESULTS}

Symptoms and disease incidence

Diseased Z. jujube plants with witches' broom, little leaf, yellowing or leaf roll symptoms in Razavi Khorasan province (Figure 1) were present in $6 \%$ of the plants in the jujube nurseries, and $4 \%$ of the plants with yellowing and thickening of leaves symptoms. 

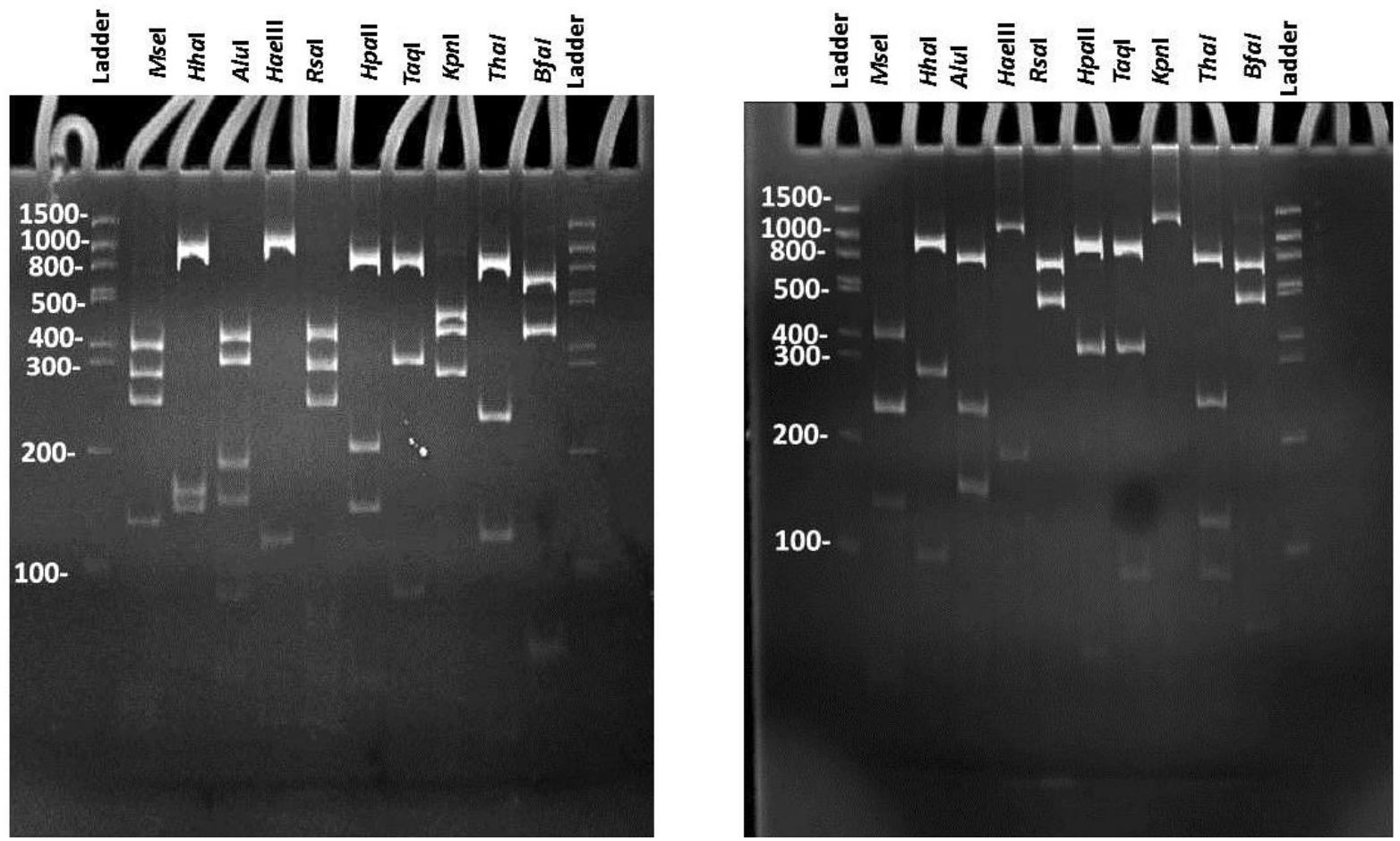

Figure 2. Polyacrylamide gel showing RFLP profiles of 16S rDNA amplified by nested PCR using P1/P7 followed by R16F2n/R16R2 primer pairs from (left) yellowing and (right) witches' broom symptomatic jujube plants. PCR products were digested by the enzymes indicated at the top of the figures; Ladder, 100 bp DNA ladder (Biobasic, Canada).
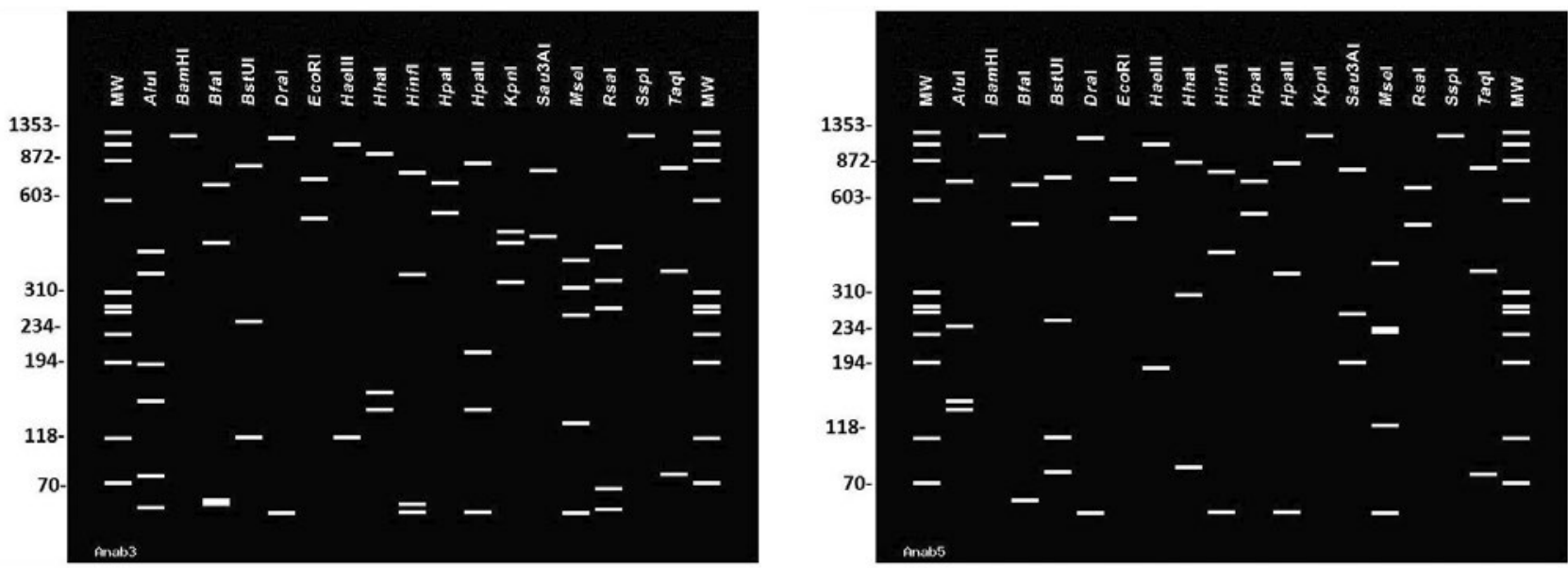

Figure 3. Virtual RFLP generated with program iPhyClassifier from in silico digestion of the R16F2n/R16R2 fragments of the (left) jujube yellowing (GenBank accession number MK379604) and (right) jujube witches' broom phytoplasma (GenBank accession number MK379605).

\section{PCR-RFLP analyses}

P1/P7 faint PCR amplicons of about $1.8 \mathrm{~kb}$ and R16F2n/R16R2 nested-PCR amplicons of $1.25 \mathrm{~kb}$, were obtained from all symptomatic $Z$. jujube plants, but not from the symptomless plants. RFLP analysis of
R16F2n/R16R2 amplicons using KpnI, HaeIII, RsaI, AluI, HpaII, HhaI, TaqI, MseI, BfaI and ThaI restriction enzymes showed two RFLP patterns, one identical to those of the 16SrI-B phytoplasma subgroup and the other identical to the 16SrVI-A subgroup (Lee et al., 1998) (Figure 2). 


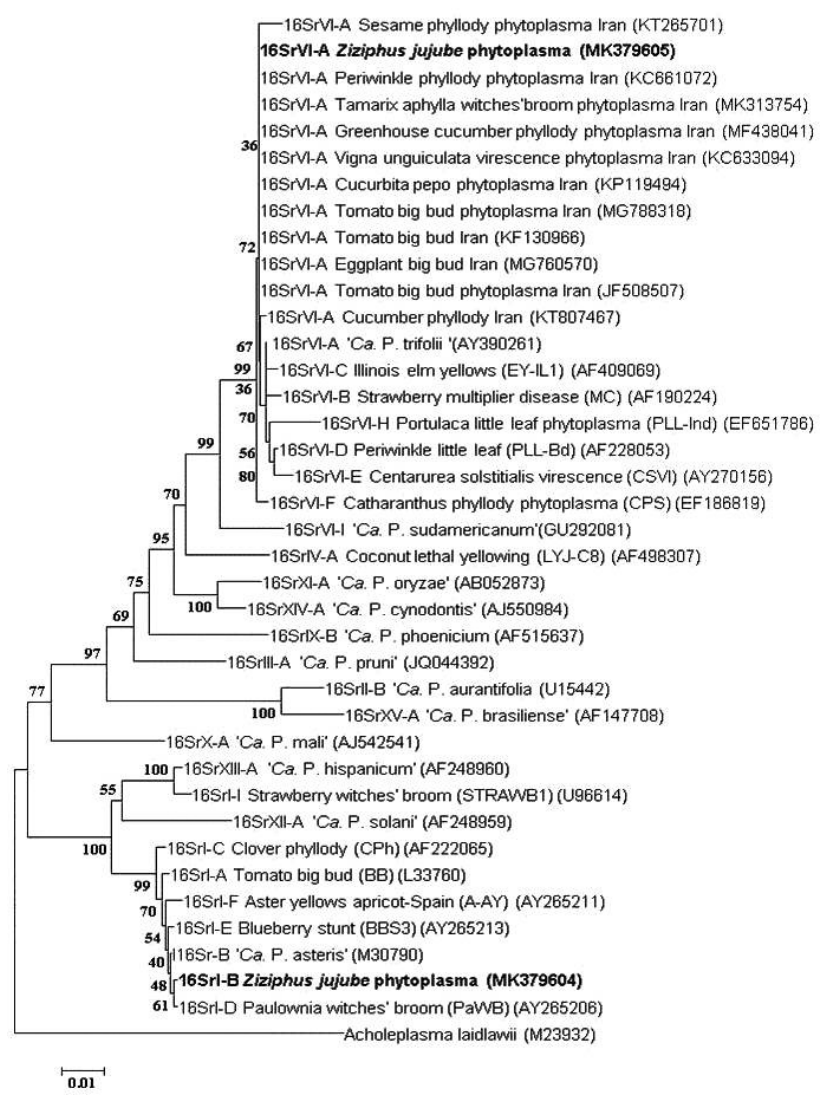

Figure 4. Phylogenetic tree constructed by the Neighbor-Joining method of 16S rRNA gene sequences from 31 phytoplasmas and Acholeplasma laidlawii, as the outgroup. The JWB phytoplasmas are indicated in bold font. Numbers at the nodes are bootstrap values based on 1,000 repetitions.

\section{Analysis of nucleotide sequences}

The $1.2 \mathrm{~kb}$ DNA fragments amplified from six samples of $Z$. jujube and two from yellowing symptoms) had sequence identity with ' $C a$. P. trifolii' related strains (four samples from witches' broom symptoms) and ' $\mathrm{Ca}$. P. asteris'-related strains (two samples from yellowing symptoms). One R16F2n/R16R2 16S rDNA sequence of each symptom was submitted to GenBank with accession numbers MK379605 and MK379604.

\section{Phylogenetic analysis and virtual RFLP}

The restriction analysis indicated that the detected phytoplasma strains were classified in the 16SrI-B and 16SrVI-A subgroups (Figure 3). Similarity coefficient and phylogenetic analyses confirmed that the phytoplasma strain associated with the yellowing symptoms was related to 'Ca. P. asteris' with $99.7 \%$ similarity to the refer- ence strain (GenBank accession number: M30790), while the phytoplasma strain associated with witches' broom symptoms was related to the 'Ca. P. trifolii' group with 99.8\% similarity with the reference strain (GenBank accession number AY390261) (Figure 4).

\section{DISCUSSION}

Direct and nested PCR assays using phytoplasma universal primers confirmed the presence of phytoplasmas in jujube plants with witches' broom and yellowing symptoms. RFLP analyses showed that phytoplasma strains associated with JWB belong to the clover proliferation ribosomal group (16SrVI-A), while jujube yellowing phytoplasmas belong to the aster yellows ribosomal group (16SrI-B). However the phytoplasma subgroup $16 \mathrm{SrV}-\mathrm{B}$ (' $\mathrm{C} a$. P. ziziphi') is the agent associated with JWB disease in different jujube varieties in China, Korea, Japan and India (Ohashi et al., 1996; Zhu et al., 1998; Fan et al., 2008; Khan et al., 2008). Phytoplasmas in the 16SrI group have only been reported in jujube trees in Korea in mixed infections with phytoplasmas of group 16SrV (Lee et al., 2009). Therefore, the present study is the first demonstration of the presence of these two phytoplasmas in jujube nurseries.

Phytoplasma groups 16SrI and 16SrVI have broad host plant ranges (Lee et al., 2004; Hiruki et al., 2004), and have also been reported from numerous and different plant hosts in Iran (Babaie et al., 2007; Salehi et al., 2016; 2018; Asghari Tazehkand et al., 2010; Rashidi et al., 2010; Esmailzadeh Hosseini et al., 2015, 2016, 2017a; Fattahi et al., 2016). This indicates that various reservoir host plants besides jujube nurseries are likely to be present.

Planning for phytoplasma disease management requires the identification of phytoplasma subgroups, to better identify the plant reservoirs and the pathways through insect vectors for entry into jujube nurseries. The phytoplasmas in 16SrI-B and 16SrVI-A in Iran are mostly transmitted by leafhopper species including Circulifer haematoceps, Macrosteles sp. and Neoaliturus haematoceps (Salehi et al., 2011; 2016). These insects are present in Iran and probably feed on other plant hosts and transmit phytoplasmas from reservoir hosts to jujube plants in nurseries. Selecting distance of nurseries from infected reservoir plants and protecting nursery plants from insect vectors is likely to assist disease management, together with the use of barrier plants or insect proof nets. Jujube cultivars resistant to phytoplasmas have been reported (Liu et al., 2006), and further research with Iranian cultivars may identify resistant varieties that can help in the disease management. How- 
ever, a certification and sanitation programme for producing healthy plant material is needed in jujube nurseries to prevent transmission of phytoplasma infections to new jujube orchards and to more geographical areas.

\section{ACKNOWLEDGEMENTS}

The authors thank CHB Agricultural Organization, and the Chaharmahal and Bakhtiari Agricultural and Natural Resources Research and Education Center, AREEO, Shahrekord, Iran, for supporting this research.

\section{LITERATURE CITED}

Asghari Tazehkand S., Hosseini Pour A., Heydarnejad J., Massumi H., Azadvar M., 2010. Identification of phytoplasmas associated with cultivated and ornamental plants in Kerman province, Iran. Journal of Phytopathology 158: 713-720.

Babaie G., Khatabi B., Bayat H., Rastgou M., Hosseini A., Salekdeh G.H., 2007. Detection and characterization of phytoplasma infecting ornamental and weed plants in Iran. Journal of Phytopathology 155: 368-372.

Deng S., Hiruki C., 1991. Amplification of 16S rRNA genes from culturable and non-culturable mollicutes. Journal of Microbiological Methods 14: 53-61.

Esmailzadeh Hosseini S.A., Salehi M., Salehi E., 2015. First report of a 16 SrI-B subgroup related phytoplasma associated with Eruca sativa phyllody in Iran. New Disease Reports 32: 22.

Esmailzadeh Hosseini S.A., Khodakaramian G., Salehi M., Bertaccini A., 2016. First report of 16SrVI-A and 16SrXII-A phytoplasmas associated with alfalfa witches' broom diseases in Iran. Journal of Plant Pathology 98: 369.

Esmailzadeh Hosseini S.A., Salehi, M., Babaie, Gh., 2017a. Occurrence and molecular characterization of a 16SrVI-A phytoplasma strain associated with greenhouse cucumber phyllody in Iran. In: Proceeding of $6^{\text {th }}$ Asian Conference on Plant Pathology, Jeju, South Korea, 232.

Esmailzadeh Hosseini S.A., Salehi M., Babaie Gh., Mohammadi S., Purmohamadi S., Bertaccini A., 2017b. Occurrence and molecular characterization of a 'Candidatus Phytoplasma omanense'-related strain associated with Prunus persica yellowing and decline in Iran. In: Proceeding of $6^{\text {th }}$ Asian Conference on Plant Pathology, Jeju, South Korea, 233.

Fan X.P., Paltrinieri S., Pastore M., Petriccione M., Wang X., ... Bertaccini A., 2008. Molecular detection of
'Candidatus Phytoplasma ziziphi' in different jujube varieties. Acta Horticulturae 772: 207-210.

Fattahi M., Salehi M., Sharzehi A., Esmailzadeh Hosseini S.A., 2016. Partial biological and molecular characteristics of a phytoplasma associated with Behshahr (Mazandaran) periwinkle phyllody. Iranian Journal of Plant Pathology 52: 135-141.

Gundersen D.E., Lee I-M., 1996. Ultrasensitive detection of phytoplasmas by nested-PCR assays using two universal primer sets. Phytopathologia Mediterranea 35: 144-151.

Han S.S., Cha B., 2002. Genetic similarity between jujube witches' broom and mulberry dwarf phytoplasmas transmitted by Hishimonus sellatus Uhler. Korean Journal Plant Pathology 18: 98-101.

Hiruki C., Wang K., 2004. Clover proliferation phytoplasma: 'Candidatus Phytoplasma trifolii'. International Journal of Systematic and Evolutionary Microbiology 54: 1349-53.

Jung H.Y., Sawayanagi T., Kakizawa S., Nishigawa H., Wei W., ... Namba S., 2003. 'Candidatus phytoplasma ziziphi', a novel phytoplasma taxon associated with jujube witches' broom disease. International Journal of Systematic and Evolutionary Microbiology 53: 1037-1041.

Khan M.S., Raj S.K., Snehi S.K., 2008. Natural occurrence of 'Candidatus Phytoplasma ziziphi' isolates in two species of jujube trees (Ziziphus spp.) in India. Plant Pathology 57: 1173.

Kim C.J., 1965. Witches' broom of jujube tree (Zizyphus jujube Mill. var. inermis Rehd.). Transmission by grafting. Korean Journal of Microbiology 3: 1-6.

Kumar S., Stecher G., Tamura K., 2016. MEGA7: Molecular evolutionary genetics analysis version 7.0 for bigger datasets. Molecular Biology Evolution 33: 18701874.

La Y., Woo K., 1980. Transmission of jujube witches' broom mycoplasma by the leafhopper Hishimonus sellatus Uhler. Journal of Korean Forestry Society 48: 29-39.

Lee J.T., 1988. Investigation on jujube diseases and their severities of incidence. Res Rept RDA (Agri Institutional Cooperation) 31: 155-161.

Lee I-M., Gundersen-Rindal D.E., Davis R.E., Bartoszyk I.M., 1998. Revised classification scheme of phytoplasmas based on RFLP analyses of 16S rRNA and ribosomal protein gene sequences. International Journal of Systematic and Evolutionary Microbiology 48: 1153-1169.

Lee I-M., Gundersen-Rindal D.E., Davis R.E., Bottner K.D., Marcone C., Seemüller E., 2004. 'Candidatus Phytoplasma asteris', a novel phytoplasma taxon 
associated with aster yellows and related diseases. International Journal of Systematic and Evolutionary Microbiology 54:1037-48.

Lee S., Han S., Cha B., 2009. Mixed infection of 16 S rDNA I and V groups of phytoplasma in a single jujube tree. The Plant Pathology Journal 25: 21-25.

Li D.K., Huang C.L., Tian J.B., Wang Y.K., Wang Y.Q., 2005. Extraction ways of high quality of DNA from Z. jujuba Mil. Molecular Plant Breeding 3: 579-583.

Liu M., Zhou J., Zhao J., Wang J., Liu P., ... Wang Y. 2006. An excellent new cultivar of chinese jujube with high resistance to jujube witches' broom disease "Xingguang". Acta Horticulturae Sinica 33: 687.

Ohashi A., Nohira T., Yamaguchi K., Kusunoki M., Shiomi T., 1996. Jujube (Zizyphus jujuba) witches' broom caused by phytoplasma in Gifu prefecture. Transcripts of Forest Society of Japan 107: 309-310.

Rashidi M., Ghosta Y., Bahar M., 2010. Molecular identification of a phytoplasma associated with Russian olive witches' broom in Iran. European Journal of Plant Pathology 127: 157-159.

Salehi M., Izadpanah K., Siampour M., 2011. Occurrence, molecular characterization and vector transmission of a phytoplasma associated with rapeseed phyllody in Iran. Journal of Phytopathology 159: 100-105

Salehi M., Esmailzadeh Hosseini S.A., Salehi E., Bertaccini A., 2016. Genetic diversity and vector transmission of phytoplasmas associated with sesame phyllody in Iran. Folia Microbiologica 62: 99-109.

Salehi M., Esmailzadeh Hosseini S.A., Salehi E., 2018. First report of a 'Candidatus Phytoplasma asteris'related strain (16SrI-B) associated with Sonchus oleraceus (common sowthistle) phyllody disease in Iran. New Disease Reports 37: 6.

Schneider B., Seemüller E., Smart C.D., Kirkpatrick B.C., 1995. Phylogenetic classification of plant pathogenic mycoplasma-like organisms or phytoplasmas. In: Molecular and Diagnostic Procedures in Mycoplasmology (S.Razin, J.G. Tully, ed.), Academic Press, San Diego, CA, USA, 369-380.

Tsai J.H., Chen X.Y., Shen C.Y., Jin K.X., 1988. Mycoplasmas and fastidious vascular prokaryotes associated with tree disease in China. In: Tree Mycoplasmas and Mycoplasma Diseases (C.J. Hiruki, ed.), Alberta Press, Canada, 69-96.

Zhao Y., Wei W., Lee I.-M., Shao J., Suo X., Davis R.E., 2009. Construction of an interactive online phytoplasma classification tool, $i$ PhyClassifier, and its application in analysis of the peach X-disease phytoplasma group (16SrIII). International Journal of Systematic and Evolutionary Microbiology 59: 25822593.
Zhu S.F., Hadidi A., Lee I-M., Gundersen D.E., Zhang C.L., 1998. Characterization of the phytoplasmas associated with cherry lethal yellows and jujube witches' broom disease in China. Acta Horticulture 472: 701-707. 